\title{
influencia de la aireación de clínkeres y cementos sobre sus propiedades físicas y mecánicas
}

\author{
influence de l'éventement des clinkers et des ciments sur leurs \\ propriefés physiques et mécaniques
}

M. VENUAT

(aRev. Mat, Constr. et Trav, Publ, (Edition C)w, n. 523, abril 1959, pág. 79.)

El autor señala, en primer término, los ensayos a realizar sobre las principales características del cemento, en particular sobre tiempo de fraguado, resistencias mecánicas y tiempos de fisuración en anillos de pasta pura. La base para la redacción de este trabajo partió de las divergencias observadas en los tiempos de fisuración en el anillo de pasta pura, unido a una propuesta de los fabricantes para conocer la influencia del envejecimiento del clínker sobre las propiedades del cemento; a continuación se estudiaron las características principales del cemento en función de su aireación.

Las conclusiones a que llega el autor son las siguientes:

Un clinker conservado al aire varía poco cuando la atmósfera de conservación presenta una humedad relativa, inferior al $75 \%$; para un $90 \%$ de dicha humedad se afectan sus propiedades, al pasar algunos meses, reduciéndose notablemente sus resistencias mecánicas.

El ensilado del cemento, una vez molido, es importante en el caso de ser rico en cal libre; con ello se apaga y carbonata dicha cal que, de otro modo, motivaria importantes expansiones.

El cemento colocado en un compartimiento estanco se conserva bien sin variaciones notables en su calidad.

De los estudios de cementos, conservados en aire de 50-65 \% de humedad relativa, se deduce que una aireación superior a unos días retarda el fraguado y disminuye las resistencias mecánicas, singularmente en las primeras edades. Como era de esperar, los cementos más finos son los más sensibles a la aireación.

Finalmente, del estudio de la aireación de un cemento caliente en una atmósfera de $65 \%$ de humedad relativa y $20^{\circ} \mathrm{C}$ de temperatura, deduce el autor un aumento del tiempo de fraguado y una disminución del calor de hidratactón y resistencias mecánicas, sobre todo en las primeras edades. La trascendencia de estos fenómenos se encuentra intimamente ligada a la composición mineralógica del cemento, siendo especialmente importante en los supercementos de elevado contenido en $\mathbf{C}_{3} \mathbf{S}$.

F. S. S. 